\title{
Low-Cycle Fatigue Behaviors of Pre-Corroded Q345R Steel under Wet $\mathrm{H}_{2} \mathrm{~S}$ Environments
}

\author{
Luo Yun-Rong ${ }^{1,3}, F_{u}$ Lei $^{1,2 *}$, Zeng Tao1, Lin Haibo ${ }^{1,3}$ and Chen Yanqiang ${ }^{1}$ \\ ${ }^{1}$ College of Mechanical Engineering, Sichuan University of Science and Engineering, Zigong, 643000, China \\ ${ }^{2}$ School of Aeronautics and Astronautics, Sichuan University, Chengdu 610065, PR China \\ ${ }^{3} \mathrm{Key}$ Lab in Sichuan Colleges on Industry Process Equipments and Control Engineering, Zigong, China
}

\begin{abstract}
Low cycle fatigue (LCF) behaviors of pre-corroded Q345R steel under different corrosion environments were investigated where both concentration of $\mathrm{H}_{2} \mathrm{~S}$ solution and pre-corrosion time served as two environmental factors. Low cycle fatigue tests were conducted at room temperature in air after the specimens were pre-corroded in $\mathrm{H}_{2} \mathrm{~S}$ solution. The low cycle fatigue behaviours of pre-corrosion test material, such as strain-life relationships and cyclic stress-strain responses were investigated and compared. Results show that environmental factors had little effect on the cyclic stress response while it had much effect on the fatigue life. And pre-corrosion time had more significant effect on low cycle fatigue life of test material than the solution concentration of $\mathrm{H}_{2} \mathrm{~S}$. Furthermore, the fracture surfaces of the fatigue samples were characterized by scanning electron microscope (SEM) and the fracture mechanisms were discussed under different environmental conditions.
\end{abstract}

Keywords: Q345R; Pre-corroded; Wet H2S environments; Low cycle fatigue

\section{Introduction}

Q345R steel is one of the C-Mn steels widely used in pressure vessels in China, and almost one half of the pressure vessels for medium-low pressure are made of Q345R steel [1,2].

Q345R steel is a promising material for pressure vessels because of its favorable mechanical properties and corrosion resistance. Engineering components subjected to cyclic loading often fail due to fatigue. Its low cycle fatigue behaviors have attracted numerous interests during the past years. However, the pressure vessels in oil industry have to be exposed to severe conditions, where low-cycle fatigue is a predominant failure mode [3] and the surrounding environment contains $\mathrm{H}_{2} \mathrm{~S}$ corrosion solution caused by hydrogen sulfide [4]. During its service, pre-corroded low cycle fatigue is prone to occurring to the pressure vessels under alternate loading and wet $\mathrm{H}_{2} \mathrm{~S}$ corrosion environments. Therefore, it is of great significance to investigate the effect on the lowcycle fatigue behavior of pre-corroded Q345R steel.

There are some literatures on the fatigue properties of Q345R steel. For example, FAN Zhichao [5] investigated the LCF behavior of Q345R under stress control at elevated temperature, and the effects of temperature on fatigue properties and cyclic stress response were obtained. It has been found that Q345R steel exhibited the cyclic hardening and massing behavior at $300^{\circ} \mathrm{C}$ and $420^{\circ} \mathrm{C}$. Ying et al. [6] and Zhuang et al. [7] conducted the fatigue crack growth tests of Q345R steel at different temperatures and strain rations (R), and investigated the fatigue crack growth laws. Guangxu, Zhiwen [8], Xu and Zhifang [9] have studied the LCF fatigue behaviour of the submerged-arc welding joint of Q345R steel. The mechanisms of stress corrosion of Q345R steel have been investigated under different concentrations of $\mathrm{H}_{2} \mathrm{~S}$, temperature and $\mathrm{pH}$ values $[10,11]$.

However, the research on the low-cycle fatigue behavior in wet $\mathrm{H}_{2} \mathrm{~S}$ environment is insufficient, yet. In comparison to low cycle fatigue, precorroded low cycle fatigue studies are relatively few, and very limited information on the pre-corroded low cycle fatigue of Q345R steel is available in the literature. The present study has been conducted to investigate the low cycle fatigue behavior of pre-corroded Q345R steel in different pre-corrosion environments, and then the effects of $\mathrm{H} 2 \mathrm{~S}$ solution concentration and pre-corrosion time on the LCF behavior of Q345R steel were evaluated. The fracture mechanism of Q345R steel in wet $\mathrm{H} 2 \mathrm{~S}$ environment was investigated as well.

\section{Material and Testing Arrangements}

\section{Materials and test coupons}

The specimens were machined from Q345R hot-rolled plate with the thickness of $20 \mathrm{~mm}$. The chemical compositions and mechanical properties are given in Tables 1 and 2, respectively. The fatigue specimens used in the tests were cylindrical specimens with a gauge length of $20 \mathrm{~mm}$ and a central diameter of $7.25 \mathrm{~mm}$ as shown in Figure 1. The specimen dimensions were kept to avoid buckling phenomena under the highest compressive forces anticipated in the test program [12]. The surfaces of the specimens were carefully polished along the longitudinal direction to remove the scratches.

\section{Experimental Details and Procedures}

Pre-corroded tests were conducted with two environmental factors

\begin{tabular}{|c|c|c|c|c|c|}
\hline $\mathrm{Fe}$ & $\mathrm{C}$ & $\mathrm{Si}$ & $\mathrm{Mn}$ & $\mathrm{S}$ & $\mathrm{P}$ \\
\hline Bal. & $0.12 \sim 0.16$ & $0.35 \sim 0.50$ & $1.20 \sim 1.60$ & $0.005 \sim 0.05$ & $0.015 \sim 0.025$ \\
\hline
\end{tabular}

Table 1: Chemical constant of test material (wt.\%).

\begin{tabular}{|c|c|c|c|}
\hline $\begin{array}{c}\text { 0.2\% proof } \\
\text { strength }\end{array}$ & Tensile strength & Elongation & Reduction of area \\
\hline $350 \mathrm{MPa}$ & $530 \mathrm{MPa}$ & 0.27 & 0.64 \\
\hline
\end{tabular}

Table 2: Mechanical properties of test material.

*Corresponding author: Fu Lei, Lecturer, School of Aeronautics and Astronautics College of Mechanical Engineering, Sichuan University of Science and Engineering, Zigong, 643000, PR China, Tel: +86-15808230830; E-mail: kunmingfulei@126.com

Received July 18, 2017; Accepted August 07, 2017; Published August 18, 2017

Citation: Yun-Rong L, Lei F, Tao Z, Haibo L, Yanqiang C (2017) Low-Cycle Fatigue Behaviors of Pre-Corroded Q345R Steel under Wet $\mathrm{H}_{2} \mathrm{~S}$ Environments. J Material Sci Eng 6: 367. doi: 10.4172/2169-0022.1000367

Copyright: () 2017 Yun-Rong L, et al. This is an open-access article distributed under the terms of the Creative Commons Attribution License, which permits unrestricted use, distribution, and reproduction in any medium, provided the original author and source are credited. 


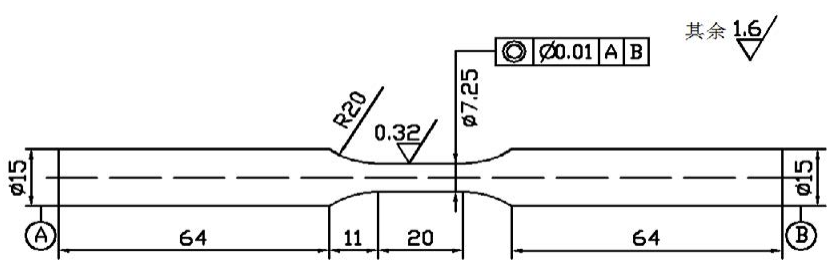

Figure 1: Geometry of specimen.

\begin{tabular}{|c|c|c|c|c|}
\multicolumn{3}{|c|}{ Test arrangement } & \multicolumn{3}{|c|}{$\mathbf{H}_{2}$ S solution's concentration H } \\
\cline { 2 - 5 } & & $\mathbf{0 . 0 5 \%}(\mathbf{w t} . \%)$ & $\mathbf{0 . 1} \%$ (wt. \%) & $\mathbf{0 . 2} \%$ (wt. \%) \\
\hline $\begin{array}{c}\text { Pre-corrosion } \\
\text { time D }\end{array}$ & $7 \mathrm{~d}$ & H05D7 & H1D7 & H2D7 \\
\cline { 2 - 5 } & $15 \mathrm{~d}$ & H05D15 & H1D15 & H2D15 \\
\cline { 2 - 5 } & $30 \mathrm{~d}$ & H05D30 & H1D30 & H2D30 \\
\hline
\end{tabular}

Table 3: The pre-corroded experimental arrangement.

including corrosion solution's concentration and pre-corrosion time. Three levels have been selected for each factor according to the actual working condition [13]. The concentration of $\mathrm{H}_{2} \mathrm{~S}$ solution was set to $0.05 \%, 0.1 \%$ and $0.2 \%$ (wt, $\%$ ), and the pre-corrosion time was set to 7 days (d), 15 days (d) and 30 days (d). Therefore, a total of 9 test groups were designed and the pre-corroded test arrangement is shown in Table 3. To maintain a stable corrosion solution's concentration, the solution was renewed every 7 days for those test groups of more than 7 days of corrosion time [14].

Low-cycle fatigue (LCF) tests were carried out on the MTS-809 fatigue test machine at room temperature in air. The LCF tests were conducted under total strain control at constant strain amplitude $\left(\varepsilon_{o}\right)$ ranging from $0.4 \%$ to $0.8 \%$. Triangular waveform was employed for all the fatigue tests at the frequency of $1 \mathrm{~Hz}$. The cyclic loading was started from the tensile side. The total strain was measured by a dynamic extensometer with the span length of $10.0 \mathrm{~mm}$ which was attached to the specimen. The data was considered invalid for the tests with fracture outside the gage length of the dynamic extensometer. The fatigue life $\left(\mathrm{N}_{\mathrm{f}}\right)$ was defined as the number of cycles when the peak tensile stress decreased to $75 \%$ of the maximum peak stress. The response at half of the fatigue life was used to obtain cyclic stress-strain curves in this study. After the low-cycle fatigue tests, the fatigue fracture surfaces of the specimens were observed by a scanning electron microscope (SEM) (TESCAN: VEGA 3 EasyProbe).

\section{Results and Discussion}

\section{Cyclic stress response}

Figure 2 shows the cyclic stress-strain curves of the test material in different test environments. Cyclic stress-strain curve is an important indication under cyclic loading, which could reflect the real stressstrain relationship of the test material. Figure 2a illustrates the difference between the cyclic stress-strain curve and uniaxial tensile curve of the uncorroded test material. It can be seen that the cyclic stress-strain curve coincide well with the uniaxial tensile curve in elastic deformation stage, which means that the low-cycle fatigue test system is under good control and the experimental data is of high reliability. In plastic deformation stage, the cyclic stress-strain curve surpassed the uniaxial tensile curve obviously, which means that Q345R steel exhibited cyclic hardening behavior. According to the regression of the experimental data, the cyclic stress-strain relationship of the test material was obtained as shown in eqn. (1). Figure $2 \mathrm{~b}$ shows the cyclic stress-strain curves of the test material in different pre-corroded

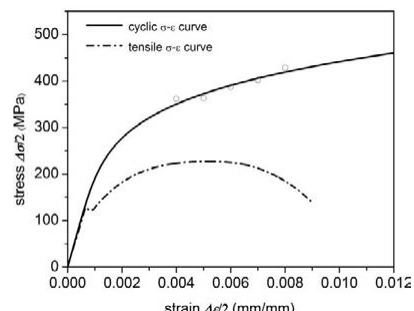

(a)

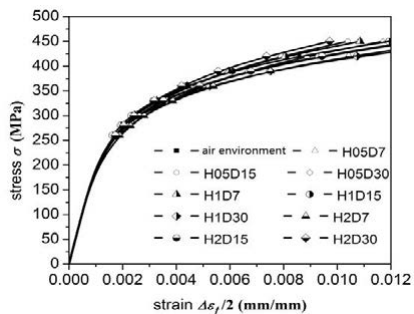

(b)
Figure 2: Cyclic stress-strain curves of Q345R steel in different test environments: (a) Comparison of cyclic stress-strain curve and uniaxial tensile curve, (b) Cyclic stress-strain curves in different environments.

\begin{tabular}{|c|c|c|c|c|c|c|}
\hline $\begin{array}{c}\text { LCF } \\
\text { parameters }\end{array}$ & $\boldsymbol{\sigma}_{\boldsymbol{f}}{ }^{\prime} \mathbf{( M P a )}$ & $\boldsymbol{b}$ & $\boldsymbol{\varepsilon}_{\boldsymbol{f}}$ & $\boldsymbol{c}$ & $\left.\boldsymbol{K}^{\prime} \mathbf{( M P a}\right)$ & $\boldsymbol{n}^{\prime}$ \\
\hline H05D7 & 904.68 & -0.097 & 1.25 & -0.63 & 1189.27 & 0.21 \\
\hline H05D15 & 985.89 & -0.102 & 0.49 & -0.54 & 1208.83 & 0.21 \\
\hline H05D30 & 893.51 & -0.092 & 0.18 & -0.44 & 1018.81 & 0.18 \\
\hline H1D7 & 1423.8 & -0.14 & 1.02 & -0.62 & 1228.49 & 0.21 \\
\hline H1D15 & 971.25 & -0.105 & 0.43 & -0.53 & 988.03 & 0.17 \\
\hline H1D30 & 734.16 & -0.074 & 0.41 & -0.53 & 940.29 & 0.17 \\
\hline H2D7 & 1200.57 & -0.131 & 0.64 & -0.57 & 1016.24 & 0.18 \\
\hline H2D15 & 796.95 & -0.08 & 0.33 & -0.51 & 1015.01 & 0.18 \\
\hline H2D30 & 796.53 & -0.082 & 0.26 & -0.49 & 1174.99 & 0.2 \\
\hline
\end{tabular}

Table 4: LCF parameters of each test group.

environments, where little difference existed among each group and the distribution is irregular. It indicates that pre-corroded damage has little effect on cycling stress response of Q345R steel, which corresponds to the results reported [12].

$$
\Delta \varepsilon_{t} / 2=\Delta \sigma / 2 E+(\Delta \sigma / 2216.32)^{1 / 0.19}
$$

\section{Strain-life relationship}

Cyclic strain-life relationship is an important indication to assess the fatigue properties and predict the fatigue life. For the low cycle fatigue test controlled by strain, cyclic strain-life relationship is generally expressed by Manson-Coffin as below.

$$
\Delta \varepsilon_{t} / 2=\Delta \varepsilon_{e} / 2+\Delta \varepsilon_{p} / 2=\sigma_{f}^{\prime} / E\left(2 N_{f}\right)^{b}+\varepsilon^{\prime}{ }_{f}\left(2 \mathrm{~N}_{\mathrm{f}}\right)^{\mathrm{c}}
$$

where $\Delta \varepsilon_{t}$ is total strain range (\%), $\Delta \varepsilon_{e}$ is elastic strain range (\%), $\Delta \varepsilon_{p}$ is plastic strain range (\%), $\sigma_{f}{ }^{\prime}$ is fatigue strength coefficient, $\varepsilon_{f}{ }^{\prime}$ is fatigue ductility coefficient, $b$ is fatigue strength exponent, $c$ is fatigue ductility exponent, $E$ is the Young's modulus (Mpa) and $N_{f}$ is the fatigue life (cycle). According to the tests results, the material constants of each test group were obtained as shown in Table 4. Particularly, the cyclic strain-life relationship in uncorroded test environment was shown in eqn. (3).

$$
\Delta \varepsilon_{t} / 2=0.00598\left(2 \mathrm{~N}_{f}\right)^{-0.13}+1.98\left(2 \mathrm{~N}_{f}\right)^{-0.67}
$$

Figure 3 shows the cyclic strain-life relationship of the test material in different pre-corroded environments according to eqn. (3). As it can be seen from Figure 3a, the fatigue life of the test material decreases dramatically with increasing strain amplitudes $\Delta \varepsilon_{t} / 2$ (from $0.4 \%$ to $0.8 \%)$. Elastic strain amplitude increases from $0.16 \%$ to $0.19 \%$ while plastic strain amplitude increases from $0.24 \%$ to $0.61 \%$, plastic strain amplitude is almost 2 or 3 times as much as elastic strain amplitude, which shows that plastic deformation plays a predominant role in total deformation under low-cycle fatigue loading. Figure $3 b-3 d$ show the cyclic strain-life curves of Q345R steel with three different 


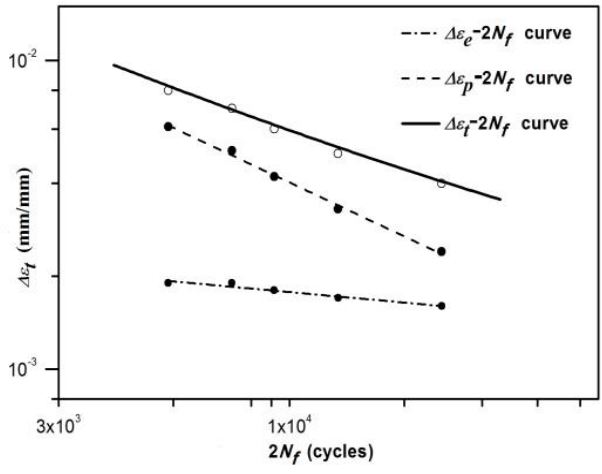

(a)

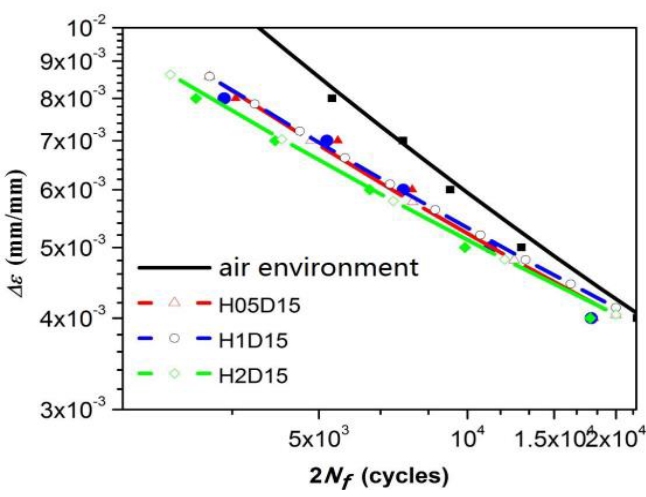

(c)

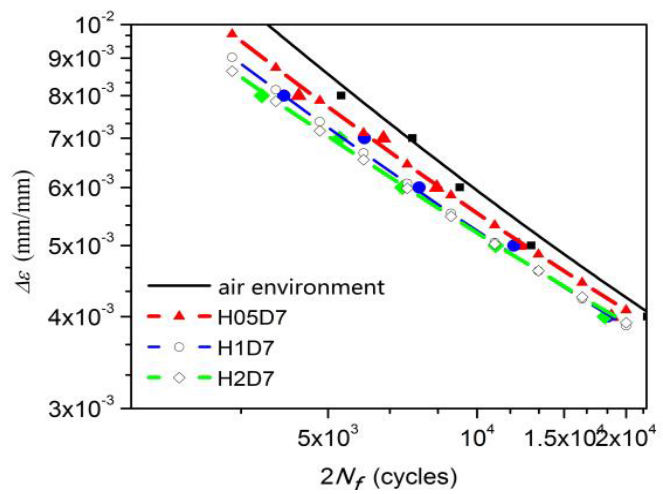

(b)

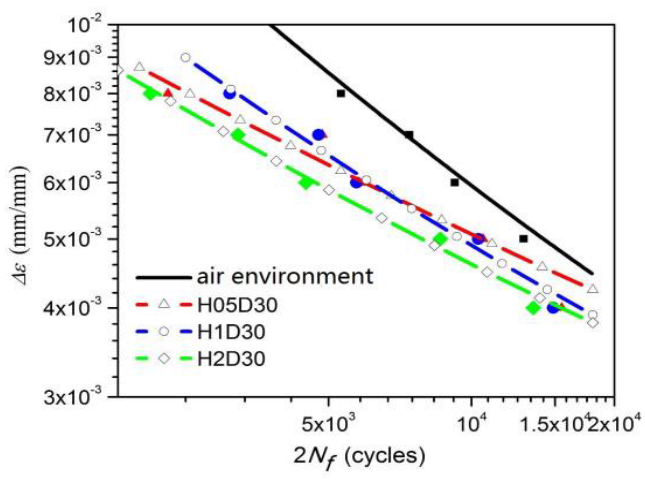

(d)

Figure 3: Strain-life curves of Q345R: (a) uncorroded, (b) in 7 days pre-corrosion environment, (c) in 15 days pre-corrosion environment, (d) in 30 days pre-corrosion environment.

$\mathrm{H}_{2} \mathrm{~S}$ solution's concentrations in 7, 15, 30 days of pre-corrosion environments, respectively. According to a series of observation and analysis, it is found that: 1 . All cyclic strain-life curves in pre-corroded environments are below the curves of the uncorroded specimens, which shows a reduction in the fatigue life as a result of the corrosion of wet $\mathrm{H}_{2} \mathrm{~S}$ environment. 2. The distance between these cyclic strainlife curves with three different $\mathrm{H}_{2} \mathrm{~S}$ solution's concentrations for the same pre-corrosion time is extremely small, even overlap each other. It indicates the cyclic strain-life relationship was independent of the change of $\mathrm{H}_{2} \mathrm{~S}$ solution's concentration. 3. The fatigue life decreases sharply with increasing pre-corrosion time (from $7 \mathrm{~d}$ to $30 \mathrm{~d}$ ) under the same strain amplitude. It can be deduced that the pre-corrosion time has a significant effect on the fatigue life of the test material. 4. The reduction rate of fatigue life increased with increasing total strain amplitude.

\section{The fracture behaviors}

In order to investigate the fracture mechanisms of Q345R steel in wet $\mathrm{H}_{2} \mathrm{~S}$ environment, fracture surfaces of samples were observed by SEM. Figure 4 shows the fracture of the uncorroded specimen fatigued, where the strain amplitude was $0.6 \%$ and the fatigue life was 4616 cycles. Figure $4 \mathrm{a}$ shows the overall fracture, which was typically consisted of crack, crack propagation and final fracture region. Multiple origins initiated at the specimen surface. The crack propagation region existed at the center of the specimen fracture, which approximately accounted for $50 \%$ of the total fracture area. Figures $4 \mathrm{~b}$ and $4 \mathrm{c}$ show the low and high magnification of crack propagation region, respectively, where typical fatigue striations, discontinued river pattern and secondary

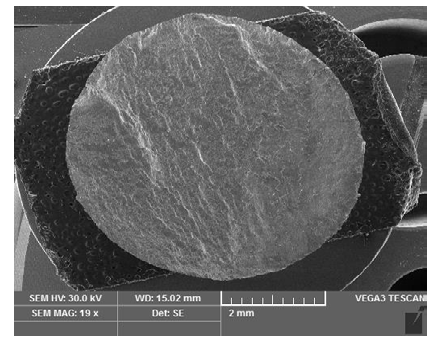

(a)

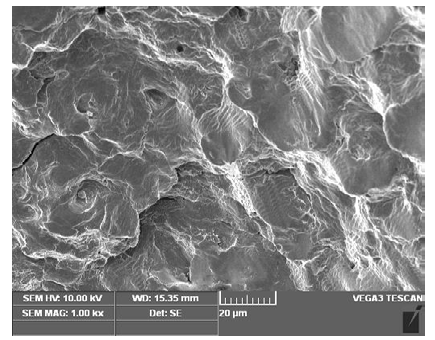

(c)

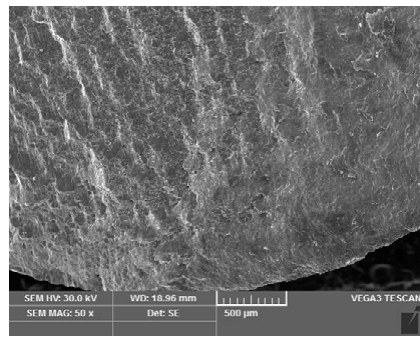

(b)

(d)

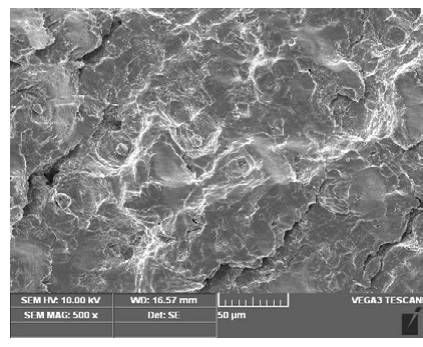

Figure 4: SEM micrographs of fracture surfaces fatigued in uncorroded environment.

cracks were observed. It indicates that the fracture behavior of the crack propagation region was quasi-cleavage fracture. Figure $4 \mathrm{~d}$ shows the microstructure of the final fracture region, where shear lips occurred. The specimen was plastic fracture characterized by dimples with tyre- 
Citation: Yun-Rong L, Lei F, Tao Z, Haibo L, Yanqiang C (2017) Low-Cycle Fatigue Behaviors of Pre-Corroded Q345R Steel under Wet $\mathrm{H}_{2} \mathrm{~S}$ Environments. J Material Sci Eng 6: 367. doi: 10.4172/2169-0022.1000367

Page 4 of 4

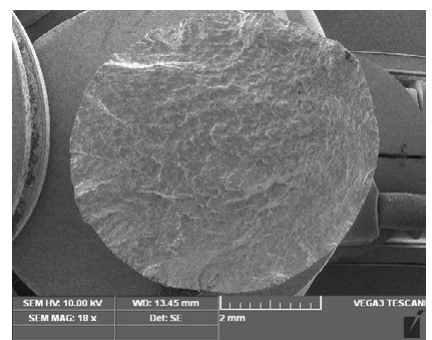

(a)

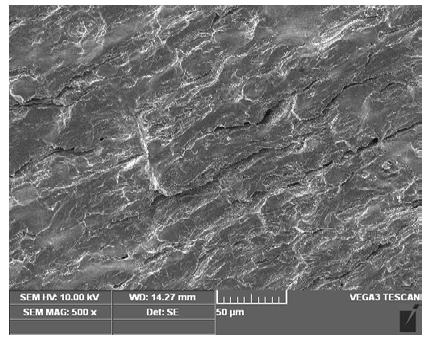

(c)

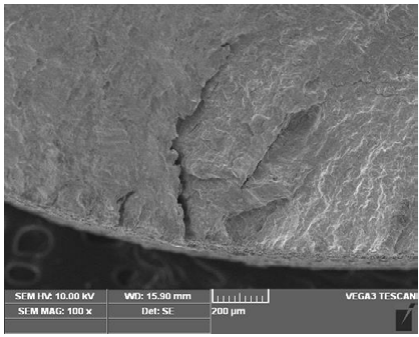

(b)

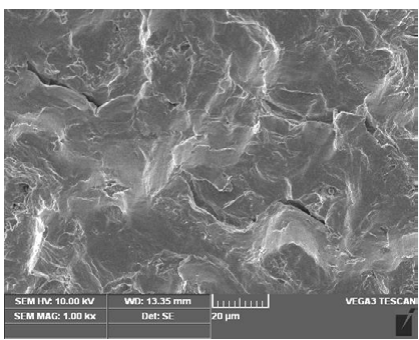

(d)
Figure 5: SEM micrographs of fracture surfaces fatigued in the pre-corroded test environment of wet $\mathrm{H}_{2} \mathrm{~S}$.

like patterns and tiny secondary cracks. The fatigue striation with tyrelike patterns is typical fracture characteristics of LCF.

Figure 5 shows the SEM fractograph of the specimen fatigued in $\mathrm{H} 2 \mathrm{D} 30$ test environment, where the strain amplitude was $0.6 \%$ and the fatigue life was 2242 cycles. As can be seen from Figure 5a, multiple crack origins initiated at the specimen surface. Figure $5 \mathrm{~b}$ shows a typical crack origins initiated from the surface and the corrosion layer with the thickness of about $10 \mu \mathrm{m}$. Figure $5 \mathrm{c}$ shows the crack propagation region, where it exhibited the quasi-cleavage fracture with discontinued river pattern, typical fatigue striations and secondary cracks. Figure $4 \mathrm{~d}$ shows the final fracture region characterized by tearing ridge, river pattern and secondary cracks. Secondary cracks existed in the whole fracture, and the length of the secondary cracks decreased while its amount increased.

\section{Conclusions}

The test results have provided useful and reliable data for the expected fatigue behavior of pre-corroded Q345R steel, which is most widely used in pressure vessel industry in China. The following conclusions can be described.

1. Pre-corroded damage caused by wet $\mathrm{H}_{2} \mathrm{~S}$ environment has little effect on cycling stress response of Q345R steel. The test material exhibited cyclic hardening.

2. The cyclic strain-life relationship was independent of the concentration of $\mathrm{H}_{2} \mathrm{~S}$ solution. However, the fatigue life of the test material reduced significantly with the increasing pre-corrosion time. The reduction rate of fatigue life increased with increasing total strain amplitudes.

3. All fractures were characterized by LCF damage features, i.e. with fatigue striations, secondary cracks and tyre-like patterns. Multiple crack origins initiated at the specimen surface. The crack propagation region was quasi-cleavage fracture, and the final fracture in pre-corroded test environment of wet $\mathrm{H}_{2} \mathrm{~S}$ is mixture characteristics of plastic fracture and brittle quasi-cleavage fracture.

\section{Acknowledgements}

This research was financially supported by National Natural Science Foundation of China under grant No. 51301115, Key Science and Technology Support Program of Sichuan Province No. 2016GZ0294, Key Laboratory of Material Corrosion and Protection of Sichuan Province under grant (No. 2012CL10. No. 2016CL17), Project of Sichuan Province Department of Education No. 16ZB0255 and Talent Introduction Projection in Sichuan University of Science and Engineering under grant No. 2015RC34.

\section{References}

1. Li C, Chen G, Chen X, Zhang W (2012) Ratcheting strain and simulation of $16 \mathrm{MnR}$ steel under uniaxial cyclic loading. Computational Materials Science 57: 43-47.

2. Zengliang G, Kangda $Z$ (1997) Comparison of the fracture and fatigue properties of $16 \mathrm{MnR}$ steel weld metal, the HAZ and the base metal. Journal of materials processing technology 63: 559-562.

3. Guangxu C (1994) The investigation of low-cycle fatigue life for pressure vessel by damage mechanics approach. Journal of Xi'an Jiaotong University 8.

4. Weizong W, Shiqun X, Penglin J (2001) Case of Corrosion Failure in Wet Hydrogen Sulfide Environment and Countermeasures. Petrochemical Corrosion and Protection 2: 002.

5. Fan ZC, Jiang JL (2004) Investigation of low cycle fatigue behavior of $16 \mathrm{MnR}$ steel at elevated temperature. Journal-Zhejiang University Engineering Science 38: 1190-1195.

6. Ying X, Bingbing C, Sanlong Z, Zengliang G (2009) Study on fatigue crack growth behavior of $16 \mathrm{MnR}$ steel under different conditions. Acta Metallurgica Sinica 45: 849-855.

7. Zhuang LJ, Gao ZL, Wang XG (2007) An experimental study and simulation of fatigue crack propagation of $16 \mathrm{MnR}$ steel. Pressure Vessel Technology 24: 1-7.

8. Guangxu C, Zhiwen L (1991) Low-cycle Fatigue Characteristic of Welding Joint for $16 \mathrm{MnR}$ Steel and Its Application to Fatigue Life Design in Pressure Vessel. Chemical Production and Technology 8(6).

9. Xu C, Zhifang Z (2000) Low Cycle Fatgue of $16 \mathrm{MnR}$ Steel Welded Joint[J] Chemical Production and Technology 7(3).

10. Tang JQ, Gong JM, Zhang XC, Tu ST (2006) Comparison on the cracking susceptibility of different low alloy steel weldments exposed to the environment containing wet $\mathrm{H}_{2} \mathrm{~S}$. Engineering Failure Analysis 13: 1057-1064.

11. Zhen L, Guodong $L$ (2006) Investigation in damage from $\mathrm{H}_{2} \mathrm{~S}$ stress corrosion of $16 \mathrm{MnR}$ steel[J]. China Petroleum Machinery 34(9).

12. GB/T15248-2008. The Test Method for Axial Loading Constant-amplitude Lowcycle Fatigue of Metallic Materials. China Standards Institution: 2008.

13. Gang Y, Liang Z, Xiaohui Z (2004) The Investigation of H2S Corrosion of $16 \mathrm{MnR}$ Steel and the Rule of Hydrogen Permeation. Journal of Hunan University(Natural Sciences) 31(3).

14. JB/T 7901-1999, Metals materials - Uniform corrosion - Methods of laboratory immersion testing[S]. 